\title{
The association between symptoms of mental disorders and health risk behaviours in Vietnamese HIV positive outpatients: a cross-sectional study
}

Truc T. Thai ${ }^{1,2^{*}}$, Mairwen K. Jones ${ }^{2}$, Lynne M. Harris ${ }^{3}$ and Robert C. Heard²

\begin{abstract}
Background: A high prevalence of symptoms of mental disorders (SOMD) has been found among people living with HIV/AIDS (PLHIV). Additionally, SOMD may impact on the prevalence of high-risk health behaviours (HRB). This study investigates the relationship between SOMD and HRB in a large sample of Vietnamese HIV positive outpatients.

Methods: A cross-sectional study was conducted with 400 outpatients at two HIV/AIDS clinics in Ho Chi Minh City, Vietnam, selected using a systematic sampling technique. Validated scales were used to measure SOMD, specifically symptoms of depression, anxiety, alcohol use disorder (AUD), substance use disorder (SUD) and HIV associated dementia (HAD). Participants completed a self-report questionnaire assessing HRB during the preceding 12 months including unsafe sexual practices and illicit drug use. Multivariable logistic regression models were used to evaluate associations between SOMD and HRB.

Results: The majority of participants (63.5\%) were male and the median age was 34.0 years. Unsafe sexual practices and illicit drug use were reported by 13.8 and $5.5 \%$ of participants. The prevalences of HAD, depression, AUD, anxiety and SUD symptoms were 39.8, 36.5, 13.3 10.5, 3.3\% respectively. There was no association between SOMD and HRB either with or without adjusting for correlates of HRB, except between symptoms of SUD and illicit drug use. PLHIV who had symptoms of SUD were more likely to use illicit drugs (adjusted Odds Ratio 81.14, 95\% Cl 12.55-524.47).

Conclusions: While the prevalence of SOMD among HIV positive outpatients was high, most SOMD were not associated with increased HRB. Only illicit drug use was predicted by symptoms of SUD. Screening PLHIV for symptoms of SUD may be useful for detecting people likely to be engaging in illicit drug use to reduce the risk of secondary disease transmission.
\end{abstract}

Keywords: Mental health disorder, Health risk behaviours, HIV/AIDS, Outpatient, Vietnam

\section{Background}

People living with HIV/AIDS (PLHIV) who are aware of their HIV-positive status may continue to engage in high-risk health behaviours (HRB) [1-3]. Unsafe sexual practices (USP) and injecting drug use among PLHIV represent important sources of secondary disease transmission $[4,5]$. Studies conducted in Russia and America

\footnotetext{
* Correspondence: ThaiThanhTruc@fphhcm.edu.vn; Truc.Thai@sydney.edu.au ${ }^{1}$ Faculty of Public Health, Ho Chi Minh City University of Medicine and Pharmacy, 159 Hung Phu Street, Ward 8, District 8, Ho Chi Minh City, Vietnam

${ }^{2}$ Faculty of Health Sciences, University of Sydney, 75 East Street, Lidcombe, Sydney, NSW 2141, Australia

Full list of author information is available at the end of the article
}

have found that up to $50 \%$ of PLHIV reported having had unprotected vaginal or anal intercourse with serodiscordant partners [3,5-7]. In Vietnam, about $20 \%$ of PLHIV reported having sex with multiple partners and less than half said that they consistently used condoms with regular or casual sexual partners [2]. Such HRB may result in HIV transmission to HIV-negative persons. Additionally, PLHIV engaging in these HRB are more likely to become infected with new HIV strains or other sexually transmitted diseases which can lead to acceleration of HIV, HIV treatment resistance, or secondary HIV transmission $[5,8,9]$. 
Substance use, regardless of the intake method, has been found to be common in PLHIV. In a sample from Russia, about 35\% of PLHIV reported injecting drug use and $63 \%$ of this group indicated that they also shared needles [3]. In Vietnam, slightly more than half (51.6\%) of a sample of 4266 PLHIV reported injecting drug use during the past month and 35\% of these reported that they had shared needles [2]. A review of 12 studies undertaken in Europe and one study conducted in the USA revealed a prevalence of recreational substance use in PLHIV of approximately $30 \%[10,11]$. Substance use has been shown to complicate HIV treatment since the acute effects of intoxication lead to difficulties with medication adherence, which may result in accelerating HIV disease progression $[12,13]$. Overall, USP, injecting drug use and other substance use can increase the likelihood that individuals will be exposed to a range of diseases such as hepatitis $B$ and $C$, herpes, syphilis, chlamydia and gonorrhoea [14, 15], further compromising the health of PLHIV. As such, research that elucidates the contributors to HRB is crucial for intervention and prevention programs.

The relationship between symptoms of mental disorders (SOMD) and HRB among PLHIV is multifaceted and complex [4]. PLHIV may experience depression or anxiety after being informed that they are HIV positive due to fear of developing AIDS, or being aware of the stigma and discrimination towards HIV/AIDS [4, 16]. Also, PLHIV who have SOMD may be at greater risk of engaging in HRB due to impaired judgment and reduced ability to accurately assess or negotiate risk [5-7]. For example, in a sample of 360 American PLHIV it was found that those who were severely depressed, socially anxious or cognitively impaired were less able to negotiate condom use [7]. Further, HRB such as substance use among PLHIV can result in manic or psychotic episodes during which the person experiences impaired judgment [17]. Finally, substance dependence can lead to HRB, such as sharing drug use equipment or engaging in unprotected sex when intoxicated, and this can result in secondary HIV infection $[4,16]$.

A meta-analysis of 34 studies conducted prior to 2000 showed little evidence to support a relationship between SOMD, HRB and presence of HIV [18]. However, this meta-analysis was criticized for methodological inadequacies including that cross-sectional studies pooled in the analysis could not demonstrate a temporal association between SOMD and HRB [19]. Several recent investigations have found a significant, positive association between SOMD and HRB in PLHIV [6, 20, 21]. For example, a longitudinal study among 851 American PLHIV demonstrated that those with symptoms of depression and anxiety engaged in increased risky sexual behaviours and substance use [20]. However, other research has found that depression and anxiety among PLHIV may reduce sexual desire, pleasure and frequency of sexual activities [22], thus resulting in a negative association between SOMD and HRB. Given the somewhat contradictory findings concerning the relationship between SOMD and HRB among PLHIV further research is required. Understanding this relationship is crucial since SOMD such as symptoms of depression, anxiety and substance use are treatable, so addressing SOMD may assist in limiting HRB among PLHIV and thus improve secondary HIV prevention [23].

Numerous factors are associated with USP, injecting drug use and other substance use among PLHIV worldwide. Predictors of USP in a sample of Indian PLHIV included being female, childless, and knowledge that partner was HIV positive [24], and predictors in American PLHIV included younger age, and absence of AIDS complications [5]. In a sample of Vietnamese PLHIV predictors of USP included lower educational attainment and higher number of sexual partners [2]. Variables not previously found to be associated with USP include ethnicity, time since HIV diagnosis, CD4 cell count, viral load [5], general health status, tuberculosis co-infection [24] and presence of other sexually transmitted diseases [3]. The predictors of illicit drug use are identical to those identified for USP, with the addition of drug dependence, higher number of HIV symptoms [25], lower level of HIV treatment adherence in American PLHIV [26], and being informed of one's HIV status in Romanian PLHIV [27]. Identifying the predictors of HRB can assist in identifying PLHIV who are most at risk of undertaking HRB and thus developing targeted strategies to reduce HRB among those at high risk, therefore leading to better health outcomes and quality of life for PLHIV in Vietnam.

In 2015, Vietnam had approximately 254,000 PLHIV with 50.8\% reporting that their HIV infection had occurred through unprotected sex and 36.1\% reporting transmission through blood contact including injecting drug use. Ho Chi Minh City (HCMC) is the centre of economic activity in Vietnam and is also recognised as having the highest number of PLHIV in Vietnam, with 49,561 PLHIV, nearly $20 \%$ of the national total in 2015 [28]. Of these, about 25,000 are registered and receive treatment at 30 HIV/AIDS outpatient clinics, mostly located at district health care centres [28]. Each clinic employs the same national guidelines for the admission and management of clients. Currently, the people most at risk of becoming infected with HIV in Vietnam are those who inject drugs, with $9.3 \%$ of this group HIV positive, compared to $2.7 \%$ of female sex workers and $5.2 \%$ of men who have sex with men [28]. While researchers have investigated factors associated with HRB among Vietnamese PLHIV including knowledge and beliefs about HIV, disclosure of HIV status, partner 
characteristics, social support, HIV treatment and health status $[2,22,29]$, there is a paucity of research investigating the relationship between SOMD and HRB in this population in Vietnam. With prevalence of depression in Vietnam estimated to be up to $40 \%$ based on screening scales [30] and 31\% using psychiatric interview [31] and given evidence that SOMD are associated with HRB in a large national sample $(N=10,783)$ in the USA [32], research examining the relationship between SOMD and HRB among PLHIV in Vietnam is warranted.

This study investigated the relationship between a range of frequently occurring SOMD, specifically symptoms of depression, anxiety, alcohol use disorder (AUD), substance use disorder (SUD) and HIV associated dementia (HAD), and their relationship with USP and illicit drug use in a large sample of Vietnamese HIV positive outpatients in HCMC.

\section{Methods}

\section{Setting and participants}

We conducted a cross-sectional study from December 2013 to March 2014 at two HIV/AIDS clinics randomly selected from the 30 public HIV/AIDS outpatient clinics in HCMC. These two clinics were selected by placing 30 envelopes each with one clinic's name in a box and randomly drawing two of the envelopes. The study was confined to two clinics due to the limitation of study resources. The study was part of a larger research project that involved all participants being interviewed by a psychiatrist and all participants being followed-up 3 months after the initial assessment. As the study required all participants to be interviewed and followed up, it was not feasible to include additional HIV clinics in the time available for the study. Details of the procedures and results from psychiatrists' interviews have been reported elsewhere [31]. The two HIV clinics were situated within district health care centers located in District 8 and District 10. These districts are two of 19 inner urban districts of HCMC. District 8 is in Southeast HCMC, comprises 16 wards and has a population of more than 420,000 people. District 10 is in Southwest HCMC, comprises 15 wards and has a population of more than 235,000 people. Each HIV clinic provides services for HIV positive outpatients who reside in the district. At any time, the HIV clinic in District 8 has about 1400 patients while the HIV clinic in District 10 has about 1300 patients, and most patients at both HIV clinics will be receiving ART. Both district health care centers where the HIV clinics are located also include departments of mental health that deliver mental health services. However, there is no formal linkage between the HIV clinics and the mental health services and no routine screening for SOMD at the HIV clinics for referral to mental health services.
The formula and parameters used for the sample size calculation were based on those used for a larger study to estimate prevalence of HIV positive outpatients who had SOMD requiring a referral to psychiatric services. In summary, with expected prevalence of 0.50 and the width of $95 \%$ confidence interval of 0.10 , at least 385 outpatients were needed [31]. With prevalence of HRB among outpatients with and without SOMD of 0.70 and 0.20 , a sample of at least 18 outpatients with SOMD and 18 outpatients without SOMD was needed to detect relationships of moderate strength with at least $80 \%$ power [31]. Therefore, a rounded number of 400 was sought, taking into account participants lost to follow up in the larger research project. Inclusion criteria were as follows: (a) at least 18 years of age; (b) sufficient literacy to respond to the questionnaire; and (c) commenced ART treatment at least 30 days previously. This final inclusion criterion was important because side-effects of the ART medication which affect physical and/or mental health are most likely to occur when ART is first initiated, so that including those who had commenced ART within 30 days may have resulted in an overestimate of the prevalence of SOMD in this population. Since a sample of 200 outpatients was sought from each HIV clinic, every fifth outpatient who met the inclusion criteria was systematically recruited on the day of their routine monthly visit based on the assigned ticket number when the patient arrived at the clinics. A total of 400 HIV positive outpatients, 200 from each clinic, agreed to participate from the 410 HIV positive outpatients initially targeted for recruitment.

\section{Procedure and measurement Self-report questionnaire}

Participants completed a self-administered questionnaire that asked about demographic characteristics, general health status, HIV status disclosure, practical, emotional, spiritual and financial support occasionally or frequently received from family, society and professionals, and number of stressful life experiences during the last 30 days. The questions about stressful life experiences were adapted from previous measures of HIV-related stress [33-35].

\section{Clinical data extraction}

The researcher (first author), with the assistance of staff at the clinics, extracted health and treatment-related data from the clinical records including weight $(\mathrm{kg})$, height $(\mathrm{m})$, time since HIV diagnosis (years), time since ARV treatment (years), most recent CD4 cell count $\left(\right.$ cells $\left./ \mathrm{mm}^{3}\right)$, HIV stage $(1,2,3,4)$, presence of other chronic diseases (Yes/No), history of delaying ARV treatment (Yes/No), history of opportunistic disease (Yes/No), adherence to HIV medications (Good/Average/Poor) and 
whether family members had been diagnosed HIV positive (Yes/No). Body mass index was calculated from weight and height and was categorized based on an Asian population. Viral load was not extracted as it is only assessed for patients with indicators of treatment failure in Vietnam and was not available for the majority of these outpatients.

\section{Symptoms of mental disorders}

Symptoms of depression were measured using the Center for Epidemiologic Studies-Depression scale (CES-D) [36]. The CES-D has 20 items and the total score ranges from 0 to 60. Cutoffs of 16, 21 and 25 have been used in previous studies to screen for depression [37] but the cutoff of 16 was used here as this has been widely used in research and recommended by the developer to indicate likelihood of clinical symptoms of depression during the past 7 days [36]. Anxiety symptoms were evaluated using the 13 item Phan Vietnamese Psychiatric Scale-Anxiety subscale (PVPS-A) [38]. Based on previous work [38] a mean score of greater than 1.60 on the PVPS-A was used to indicate probable anxiety disorder during the last 4 weeks. Symptoms of SUD were assessed using the 10-item Drug Abuse Screening Test (DAST) [39]. Cutoffs of 1, 3, 6 and 9 have been used in previous studies $[39,40]$ however the cutoff of 3 has been commonly used in studies that include people with and without drug use problems $[40,41]$ and therefore a total score of 3 or more on the DAST was used to indicate clinical symptoms of SUD during the past 12 months. Symptoms of AUD were measured by the World Health Organization Alcohol Use Disorder Identification Test (WHO-AUDIT) [42]. Cutoffs of 8, 16 and 20 have previously been used to screen for symptoms of AUD on the WHO-AUDIT [42] and we used the cutoff of 8 , as this is the most commonly reported cutoff to indicate symptoms of AUD during the last 12 months both in the general population and among PLHIV [42-44]. Symptoms of HIV associated dementia (HAD) were measured using the International HIV Dementia Scale (IHDS) [45]. A score of $\leq 10$ on the IHDS has been recommended for detecting current HIV associated dementia among PLHIV [45] and a cutoff of 10 was used in the present study. These scales have been shown to have good psychometric properties and have been used in previous studies with PLHIV [36, 38, 41, 42, 45, 46].

\section{High-risk health behaviours}

HRB was assessed by self-reported USP and illicit drug use. Illicit drug use was indicated when participants reported injecting drug or using other recreational drugs during the past 12 months. USP were identified if the participants responded that they had occasionally, frequently or very frequently had anal intercourse or vaginal intercourse with their partners or with sex workers without protection in the past 12 months.

\section{Data analysis}

Proportions for categorical variables and medians with inter-quartile ranges (IQR) for continuous variables were used to summarize the data. To detect the differences among those with and without USP or illicit drug use, we used either the Chi-squared tests or the Fisher exact tests for categorical variables and the Wilcoxon Rank Sum tests for continuous variables. Simple logistic regression models were fitted to evaluate the association between independent variables and USP or illicit drug use. Multivariable logistic regression was carried out to identify correlates of each of the outcome variables using the procedures recommended by Hosmer et al. [47]. First, independent variables with a $p$-value of $\leq 0.2$ in bivariable analyses were used in the initial multivariable logistic regression model. Then, variable retention in the next models was based on a $p$-value $<0.05$ from the initial model. Each non-significant variable from the initial model was reintroduced to assess its individual contribution to the model. Variables that contributed to a change of $>20 \%$ of estimates and the interaction such as between sex, age with SOMD were also investigated before fitting the final model. The association between SOMD and HRB was analysed using multivariable logistic regression adjusting for correlates identified in the above procedure. All analyses were carried out using Stata v13 (StataCorp, College Station, TX).

\section{Ethics}

The study was reviewed and approved by the Human Research Ethics Committee of the University of Sydney, Australia (2013/859) and the HCMC Provincial AIDS Committee, Vietnam (IRB-03-2013). All participants provided signed informed consent.

\section{Results}

\section{Participants' characteristics}

The majority of participants were male (64\%) and the median age was 34.0 (IQR 30.5-38.0) years. The median time since HIV diagnosis was 5.7 (IQR 3.2-6.7) years. Almost all participants (99.0\%) were on ART and the median number of years on treatment was 4.2 (IQR 1.8-5.9). Unsafe sexual practices and illicit drug use were reported by 13.8 and $5.5 \%$ of participants respectively. Over one third of respondents were classified with symptoms of HAD (39.8\%) and depression (36.5\%), followed by symptoms of AUD (13.3\%), anxiety (10.5\%), and SUD (3.3\%).

\section{Bivariable analysis}

Unsafe sexual practices were associated with younger age $(\mathrm{OR}=0.95,95 \%$ CI 0.90-0.99) and higher education 
level $(\mathrm{OR}=2.65$, 95\% CI 1.20-6.03), higher economic status $(\mathrm{OR}=2.27,95 \%$ CI 1.22-4.35) (Table 1$)$, poorer adherence to HIV medication (OR $=3.62$, 95\% CI $1.16-$ 11.24) (Table 2), having a family member diagnosed HIV positive $(\mathrm{OR}=2.13,95 \% \mathrm{CI} 1.19-3.81)$, receiving social support from HIV support networks $(\mathrm{OR}=2.00,95 \% \mathrm{CI}$ 1.08-3.70) and not having professional support $(\mathrm{OR}=$ 1.82, 95\% CI 1.02-3.23) (Table 3). However, USP were not associated with symptoms of depression $(\mathrm{OR}=$ $0.91,95 \%$ CI $0.50-1.65)$, anxiety $(\mathrm{OR}=1.29,95 \% \mathrm{CI}$ 0.54-3.07), AUD (OR $=0.95,95 \%$ CI $0.40-2.22)$, SUD $(\mathrm{OR}=1.15$, 95\% CI $0.25-5.31)$ or $\operatorname{HAD}(\mathrm{OR}=1.01$, 95\% CI $0.57-1.81$ ).

Illicit drug use was associated with being male $(\mathrm{OR}=$ 6.25, 95\% CI 1.41-25.00), single $(\mathrm{OR}=3.33,95 \% \mathrm{CI}$ 1.37-8.33), childless $(\mathrm{OR}=8.33,95 \%$ CI 2.44-33.33), having acquired HIV through injecting drugs $(\mathrm{OR}=6.75$, 95\% CI 2.15-21.18) (Table 1), lower body mass index (BMI) $(\mathrm{OR}=3.13,95 \% \mathrm{CI} 1.30-7.69)$ (Table 2) and having symptoms of SUD (OR $=104.17,95 \%$ CI 25.37427.71) (Table 3). However, no association was found between illicit drug use and symptoms of depression $(\mathrm{OR}=1.22$, 95\% CI $0.51-2.92)$, anxiety $(\mathrm{OR}=0.85,95 \%$ CI $0.19-3.75)$, AUD (OR $=1.04,95 \%$ CI $0.30-3.63)$ or HAD $(\mathrm{OR}=0.86$, 95\% CI 0.35-2.10).

\section{Multivariable analysis}

Initial multivariable modelling identified five potential demographic, clinical and psychosocial multivariable predictors of the USP measure of HRB. This initial modelling found a lower likelihood of USP among participants with poor economic status $(\mathrm{OR}=0.35,95 \% \mathrm{CI}$ 0.18-0.69) and those who had received professional support $(\mathrm{OR}=0.45,95 \% \mathrm{CI}$ 0.24-0.85). In contrast, HIV positive outpatients were more likely to have USP when they reported receiving social support (OR $=2.74,95 \%$ CI 1.38-5.42), had a family member who had been diagnosed HIV positive (OR $=2.28,95 \%$ CI $1.24-4.20)$ and had poor adherence to HIV medication ( $\mathrm{OR}=3.66,95 \%$ CI 1.08-12.37) (Fig. 1). The final multivariable model (Fig. 2) used these five variables as well as age and sex as control variables in a model predicting USP from SOMD. In this model, none of the measures of SOMD were associated with USP. USP was not associated with symptoms of depression (OR $=0.87,95 \%$ CI $0.45-1.66$ ), anxiety $(\mathrm{OR}=1.30,95 \%$ CI $0.50-3.38)$, AUD $(\mathrm{OR}=1.05$, 95\% CI $0.40-2.72)$, SUD (OR $=1.40,95 \%$ CI $0.27-7.34$ ) or HAD (OR $=0.94,95 \%$ CI $0.50-1.75)$.

Initial multivariable modelling identified four potential demographic, clinical and psychosocial multivariable predictors of illicit drug use. Participants who had children were less likely to report illicit drug use $(\mathrm{OR}=0.18$; 95\% CI 0.05-0.73). However, illicit drug use was positively associated with having low BMI $(\mathrm{OR}=5.86$; $95 \%$
CI 1.72-19.94), HIV acquired through injecting drugs $(\mathrm{OR}=5.25$; 95\% CI 1.24-22.13) and having symptoms of SUD (OR =90.36; 95\% CI 15.90-513.40) (Fig. 1). The final multivariable model (Fig. 2) used these four variables with the addition of sex and age as control variables in a model predicting illicit drug use from SOMD. Illicit drug use was not associated with symptoms of depression (OR $=1.26 ; 95 \%$ CI 0.47-3.41), anxiety $(\mathrm{OR}=1.08$; $95 \% \mathrm{CI} 0.21-5.70)$, AUD $(\mathrm{OR}=0.96$, $95 \% \mathrm{CI} \quad 0.24-3.90)$ or $\mathrm{HAD}(\mathrm{OR}=0.75,95 \% \mathrm{CI} 0.27-$ 2.11). However, participants who had symptoms of SUD were more likely to report illicit drug use $(\mathrm{OR}=81.14$; 95\% CI 12.55-524.47).

\section{Discussion}

This study is one of a limited number that has investigated both SOMD and HRB and the relationship between the two in a large sample of Vietnamese HIV positive outpatients. While high prevalences of SOMD such as symptoms of depression (36.5\%) and of HAD (39.8\%) were identified in our sample, and this is consistent with previous research conducted in Vietnam and other countries [30,31, 45, 48, 49], neither symptoms of depression nor of HAD were associated with USP or illicit drug use. Similarly, AUD and anxiety symptoms did not significantly predict USP or illicit drug use. Of the symptom measures used here, only the DAST, included to measure symptoms of SUD, was a significant predictor of illicit drug use.

The high prevalence of symptoms of depression and of HAD identified in our sample is consistent with previous research conducted in Vietnam where $40 \%$ of PLHIV in a northern province and $32 \%$ of HIV positive outpatients in HCMC were reported as having depression [30, 31]. The HAD prevalence indicated by the IHDS in the current study was higher than the prevalence of $11 \%$ identified by psychiatrist's interview in Vietnam [31] but was similar to prevalences reported in previous studies using the IHDS in the United States of America (37.9\%), Canada (39.4\%), and India (32.5\%) [45, 48, 49], although lower than most studies in Africa, where reported HAD prevalence has ranged from 54.4 to $85 \%$ [50,51]. Since these studies also employed the IHDS the difference in HAD prevalence might be due to HIV severity, especially at ART initiation [50]. Our findings indicate an urgent need for screening for SOMD and provision of appropriate support and treatment for HIV positive outpatients in Vietnam.

The prevalence of USP among HIV positive outpatient in this study (13.8\%) was lower than the prevalence reported by Thanh et al. [2] among PLHIV in community and commune health clinics (20\%) [2]. It is also lower than the prevalence of approximately 50\% among PLHIV in St Petersburg, Russia [3] and among PLHIV in Pennsylvania, 
Table 1 Bivariable association between health risk behaviours and socio-demographic characteristics among Vietnamese HIV positive outpatients $(N=400)$

\begin{tabular}{|c|c|c|c|c|c|c|c|c|}
\hline \multirow[t]{2}{*}{ Demographic } & \multicolumn{4}{|c|}{ Unsafe sexual practices } & \multicolumn{4}{|l|}{ Illicit drug use } \\
\hline & Yes $n(\%)$ & No $n(\%)$ & $p$ & OR $(95 \% \mathrm{Cl})$ & Yes $n(\%)$ & No $n(\%)$ & $p$ & OR $(95 \% \mathrm{Cl})$ \\
\hline \multicolumn{9}{|l|}{ Sex } \\
\hline Female & $25(17.1)$ & $121(82.9)$ & 0.137 & 1 & $2(1.4)$ & $144(98.6)$ & 0.005 & 1 \\
\hline Male & $30(11.8)$ & $224(88.2)$ & & $0.65(0.36-1.15)$ & $20(7.9)$ & $234(92.1)$ & & $6.25(1.41-25.00)$ \\
\hline \multicolumn{9}{|l|}{ Sexual orientation } \\
\hline Heterosexual & $51(14.5)$ & $300(85.5)$ & 0.370 & 1 & $18(5.1)$ & $333(94.9)$ & 0.273 & 1 \\
\hline Homosexual/Bisexual & $3(13.0)$ & $20(87.0)$ & & $0.88(0.25-3.08)$ & $1(4.3)$ & $22(95.7)$ & & $0.84(0.11-6.59)$ \\
\hline Unsure/Not answered & $1(3.8)$ & $25(96.2)$ & & $0.24(0.03-1.77)$ & $3(11.5)$ & $23(88.5)$ & & $2.41(0.66-8.79)$ \\
\hline \multicolumn{9}{|l|}{ Age in years } \\
\hline$\leq 30$ & $21(21.0)$ & $79(79.0)$ & 0.035 & 1 & $7(7.0)$ & $93(93.0)$ & 0.642 & 1 \\
\hline $31-40$ & $29(12.2)$ & $208(87.8)$ & & $0.52(0.28-0.97)$ & $13(5.5)$ & $224(94.5)$ & & $0.77(0.30-1.99)$ \\
\hline$\geq 40$ & $5(7.9)$ & $58(92.1)$ & & $0.32(0.12-0.91)$ & $2(3.2)$ & $61(96.8)$ & & $0.44(0.09-2.17)$ \\
\hline Median (IQR) & $31(30-37)$ & $34(31-38)$ & 0.022 & $0.95(0.90-0.99)$ & $33.5(29-36)$ & $34(31-38)$ & 0.526 & $0.98(0.91-1.05)$ \\
\hline \multicolumn{9}{|l|}{ Work status } \\
\hline Unemployed/Casual & $21(13.8)$ & $131(86.2)$ & 0.893 & 1 & $8(5.3)$ & $144(94.7)$ & 0.862 & 1 \\
\hline Part-time & $9(13.0)$ & $60(87.0)$ & & $0.94(0.40-2.16)$ & $4(5.8)$ & $65(94.2)$ & & $1.11(0.32-3.81)$ \\
\hline Full-time & $16(12.7)$ & $110(87.3)$ & & $0.91(0.45-1.82)$ & $6(4.8)$ & $120(95.2)$ & & $0.90(0.30-2.67)$ \\
\hline Not working & $9(17.0)$ & $44(83.0)$ & & $1.28(0.54-2.99)$ & $4(7.5)$ & $49(92.5)$ & & $1.47(0.42-5.09)$ \\
\hline \multicolumn{9}{|l|}{ Highest level of education completed } \\
\hline$\leq$ Primary school & $20(14.4)$ & $119(85.6)$ & 0.030 & $1^{\mathrm{a}}$ & $8(5.8)$ & $131(94.2)$ & 0.873 & 1 \\
\hline Secondary school & $13(8.6)$ & $138(91.4)$ & & $0.56(0.27-1.17)$ & $9(6.0)$ & $142(94.0)$ & & $1.04(0.39-2.77)$ \\
\hline$\geq$ High school & $22(20.0)$ & $88(80.0)$ & & $1.49(0.76-2.89)$ & $5(4.5)$ & $105(95.5)$ & & $0.78(0.25-2.45)$ \\
\hline \multicolumn{9}{|l|}{ Marital status } \\
\hline Single & $14(11.3)$ & $110(88.7)$ & 0.620 & 1 & $14(11.3)$ & $110(88.7)$ & 0.002 & $1^{b}$ \\
\hline Married/Living as a couple & $33(15.1)$ & $186(84.9)$ & & $1.39(0.71-2.72)$ & $8(3.7)$ & $211(96.3)$ & & $0.30(0.12-0.73)$ \\
\hline Divorced/Separated/Widowed & $8(14.0)$ & $49(86.0)$ & & $1.28(0.51-3.26)$ & 0 & $57(100)$ & & NA \\
\hline \multicolumn{9}{|l|}{ Parental status } \\
\hline Yes & $29(13.2)$ & $190(86.8)$ & 0.746 & $0.91(0.51-1.61)$ & $3(1.4)$ & $216(98.6)$ & $<0.001$ & $0.12(0.03-0.41)^{c}$ \\
\hline No & $26(14.4)$ & $155(85.6)$ & & 1 & $19(10.5)$ & $162(89.5)$ & & 1 \\
\hline \multicolumn{9}{|l|}{ Religious affiliation } \\
\hline Yes & $16(15.4)$ & $88(84.6)$ & 0.574 & $1.20(0.64-2.25)$ & $5(4.8)$ & $99(95.2)$ & 0.719 & $0.83(0.30-2.31)$ \\
\hline No & $39(13.2)$ & $257(86.8)$ & & 1 & $17(5.7)$ & $279(94.3)$ & & 1 \\
\hline \multicolumn{9}{|l|}{ Economic status } \\
\hline Very poor/Poor & $15(8.6)$ & $159(91.4)$ & 0.009 & 1 & $11(6.3)$ & $163(93.7)$ & 0.527 & $1.32(0.56-3.12)$ \\
\hline Average/Rich & $40(17.7)$ & $186(82.3)$ & & $2.27(1.22-4.35)$ & $11(4.9)$ & $215(95.1)$ & & 1 \\
\hline \multicolumn{9}{|l|}{ Source of HIV infection } \\
\hline Sexual transmission & $34(15.2)$ & $190(84.8)$ & 0.211 & 1 & $4(1.8)$ & $220(98.2)$ & 0.001 & 1 \\
\hline Injected drug use & $11(9.2)$ & $108(90.8)$ & & $0.57(0.28-1.17)$ & $13(10.9)$ & $106(89.1)$ & & $6.75(2.15-21.18)$ \\
\hline Others & $10(17.5)$ & $47(82.5)$ & & $1.19(0.55-2.58)$ & $5(8.8)$ & $52(91.2)$ & & $5.29(1.37-20.38)$ \\
\hline
\end{tabular}

${ }^{\mathrm{a} O R} \geq$ High school vs secondary school $=2.65,95 \% \mathrm{Cl} 1.20-6.03$

${ }^{\mathrm{b}} \mathrm{OR}$ Single vs Married/Living as couple $=3.33,95 \% \mathrm{Cl} 1.37-8.33$

${ }^{C}$ Reversed OR $=8.33 ; 95 \% \mathrm{Cl} 2.44-33.33$ 
Table 2 Bivariable association between health risk behaviours and clinical factors among Vietnamese HIV positive outpatients ( $N=400$ )

\begin{tabular}{|c|c|c|c|c|c|c|c|c|}
\hline \multirow[t]{2}{*}{ Clinical factors } & \multicolumn{4}{|c|}{ Unsafe sexual practice } & \multicolumn{4}{|l|}{ Illicit drug use } \\
\hline & Yes $n(\%)$ & No $n(\%)$ & $p$ & OR $(95 \% \mathrm{Cl})$ & Yes $n(\%)$ & No $n(\%)$ & $p$ & OR $(95 \% \mathrm{Cl})$ \\
\hline \multicolumn{9}{|l|}{ General health status } \\
\hline Poor/Fair & $33(14.5)$ & $194(85.5)$ & 0.600 & $1.17(0.65-2.08)$ & $11(4.8)$ & $216(95.2)$ & 0.511 & $0.75(0.32-1.77)$ \\
\hline Very good/Good & $22(12.7)$ & $151(87.3)$ & & 1 & $11(6.4)$ & $162(93.6)$ & & 1 \\
\hline \multicolumn{9}{|l|}{ Body Mass Index } \\
\hline Under-weight & $13(10.7)$ & $108(89.3)$ & 0.369 & 1 & $13(10.7)$ & $108(89.3)$ & 0.011 & 1 \\
\hline Normal & $35(14.4)$ & $208(85.6)$ & & $1.40(0.71-2.75)$ & $9(3.7)$ & $234(96.3)$ & & $0.32(0.13-0.77)^{\mathrm{a}}$ \\
\hline Overweight & $7(19.4)$ & 29 (80.6) & & $2.01(0.73-5.48)$ & 0 & $36(100)$ & & NA \\
\hline \multicolumn{9}{|c|}{ Time since HIV diagnosis in years } \\
\hline Median (IQR) & $5.3(2.8-6.8)$ & $5.8(3.5-6.7)$ & 0.143 & $0.91(0.81-1.02)$ & $4.3(2.4-6)$ & $5.8(3.3-6.7)$ & 0.101 & $0.87(0.73-1.04)$ \\
\hline \multicolumn{9}{|c|}{ Most recent CD4 cell count } \\
\hline Median (IQR) & $381(282-642)$ & $422(274-582)$ & 0.885 & $1.02(0.91-1.14)^{b}$ & $412.5(210-567)$ & $418.5(279-587)$ & 0.593 & $0.94(0.79-1.13)^{b}$ \\
\hline \multicolumn{9}{|c|}{ Time since ARV treatment in years } \\
\hline Median (IQR) & $3.80(1.80-5.60)$ & $4.22(1.78-6.03)$ & 0.448 & $0.95(0.84-1.08)$ & $2.0(1.6-5.4)$ & $4.24(1.82-5.91)$ & 0.080 & $0.82(0.67-1.00)$ \\
\hline \multicolumn{9}{|l|}{ Current HIV stage } \\
\hline 1 & $51(13.9)$ & $317(86.1)$ & 0.484 & 1 & $20(5.4)$ & $348(94.6)$ & 0.411 & 1 \\
\hline 2 & 0 & $10(100)$ & & NA & 0 & $10(100)$ & & NA \\
\hline 3 & $3(17.6)$ & $14(82.4)$ & & $1.33(0.37-4.80)$ & $1(5.9)$ & $16(94.1)$ & & $1.09(0.14-8.62)$ \\
\hline 4 & $1(20.0)$ & $4(80.0)$ & & $1.55(0.17-14.18)$ & $1(20.0)$ & $4(80.0)$ & & $4.35(0.46-40.75)$ \\
\hline \multicolumn{9}{|c|}{ Presence of other chronic diseases } \\
\hline Yes & $13(13.4)$ & $84(86.6)$ & 0.909 & $0.96(0.49-1.88)$ & $5(5.2)$ & $92(94.8)$ & 0.864 & $0.91(0.33-2.55)$ \\
\hline No & $42(13.9)$ & $261(86.1)$ & & 1 & $17(5.6)$ & $286(94.4)$ & & 1 \\
\hline \multicolumn{9}{|c|}{ History of delaying ARV treatment } \\
\hline Yes & $2(8.3)$ & $22(91.7)$ & 0.757 & $0.56(0.13-2.45)$ & $2(8.3)$ & $22(91.7)$ & 0.634 & $1.60(0.35-7.29)$ \\
\hline No & $52(14)$ & $320(86.0)$ & & 1 & $20(5.4)$ & $352(94.6)$ & & 1 \\
\hline \multicolumn{9}{|c|}{ History of opportunistic disease diagnosis } \\
\hline Yes & $32(12.5)$ & $225(87.5)$ & 0.312 & $0.74(0.42-1.33)$ & $16(6.2)$ & $241(93.8)$ & 0.393 & $1.52(0.58-3.96)$ \\
\hline No & $23(16.1)$ & $120(83.9)$ & & 1 & $6(4.2)$ & $137(95.8)$ & & 1 \\
\hline \multicolumn{9}{|c|}{ Adherence to HIV medications } \\
\hline Good & $49(13.3)$ & $319(86.7)$ & 0.036 & 1 & $20(5.4)$ & $348(94.6)$ & 0.180 & 1 \\
\hline Average & $1(5.6)$ & $17(94.4)$ & & $0.38(0.05-2.94)$ & 0 & $18(100)$ & & NA \\
\hline Poor & $5(35.7)$ & $9(64.3)$ & & $3.62(1.16-11.24)$ & $2(14.3)$ & $12(85.7)$ & & $2.90(0.61-13.85)$ \\
\hline
\end{tabular}

${ }^{\mathrm{a}}$ Reversed OR $=3.13 ; 95 \% \mathrm{Cl} 1.30-7.69$

${ }^{\mathrm{b}}$ For every 100 units change

USA [5] and the 34\% reported among PLHIV in Las Vegas Valley, USA [7]. Many Vietnamese PLHIV hold the incorrect belief that sexual activity weakens the body and that reducing or avoiding sexual activity can protect one's health [22] and so it is possible that the HIV positive outpatients in the present study have chosen to reduce or avoid sexual activity in order to improve their health. Another possible factor that might explain this difference was the lower prevalence of symptoms of depression found in the earlier studies, since a qualitative study among Vietnamese PLHIV found that depression can reduce sexual desire, pleasure and frequency of sexual activities [22].
In our study only $5.5 \%$ of participants reported illicit drug use during the past 12 months while Thanh et al. [2] reported injecting drug use during the past month to be $51.6 \%$ in a Vietnamese sample of PLHIV [2]. This discrepancy between findings is perhaps surprising, particularly given that we assessed any illicit drug use, including, but not limited to, injected substances, while Thanh et al. assessed injecting drug use specifically. It would be expected that a higher proportion of PLHIV would engage in illicit drug use compared to injecting drug use only. While it is difficult to reconcile the differences in findings across the two studies, and further research will need to 
Table 3 Bivariable association between health risk behaviours and psychosocial factors among Vietnamese HIV positive outpatients $(N=400)$

\begin{tabular}{|c|c|c|c|c|c|c|c|c|}
\hline \multirow{2}{*}{$\begin{array}{l}\text { Psychosocial and } \\
\text { mental health factors }\end{array}$} & \multicolumn{4}{|c|}{ Unsafe sexual practices } & \multicolumn{4}{|c|}{ Illicit drug use } \\
\hline & Yes $n(\%)$ & No $n(\%)$ & $P$ & OR $(95 \% \mathrm{Cl})$ & Yes $n(\%)$ & No $n(\%)$ & $p$ & OR $(95 \% \mathrm{Cl})$ \\
\hline \multicolumn{9}{|c|}{ Have family members diagnosed HIV positive } \\
\hline Yes & $25(20.5)$ & $97(79.5)$ & 0.009 & $2.13(1.19-3.81)$ & $3(2.5)$ & $119(97.5)$ & 0.096 & $0.34(0.10-1.18)$ \\
\hline No & $30(10.8)$ & $248(89.2)$ & & 1 & $19(6.8)$ & $259(93.2)$ & & 1 \\
\hline \multicolumn{9}{|l|}{ HIV status disclosure } \\
\hline Yes & $50(13.7)$ & $314(86.3)$ & 0.999 & $0.99(0.37-2.66)$ & $21(5.8)$ & $343(94.2)$ & 0.708 & $2.14(0.28-16.41)$ \\
\hline No & $5(13.9)$ & $31(86.1)$ & & 1 & $1(2.8)$ & $35(97.2)$ & & 1 \\
\hline \multicolumn{9}{|l|}{ Family support } \\
\hline Yes & $48(13.3)$ & $312(86.7)$ & 0.468 & $0.73(0.30-1.73)$ & $22(6.1)$ & $338(93.9)$ & 0.149 & NA \\
\hline No & $7(17.5)$ & $33(82.5)$ & & 1 & 0 & $40(100)$ & & \\
\hline \multicolumn{9}{|l|}{ Social support } \\
\hline Yes & $19(20.9)$ & $72(79.1)$ & 0.025 & $2.00(1.08-3.70)$ & $7(7.7)$ & $84(92.3)$ & 0.297 & $1.63(0.64-4.14)$ \\
\hline No & $36(11.7)$ & $273(88.3)$ & & 1 & $15(4.9)$ & $294(95.1)$ & & 1 \\
\hline \multicolumn{9}{|l|}{ Professional support } \\
\hline Yes & $27(11.0)$ & $219(89.0)$ & 0.042 & $0.55(0.31-0.98)^{a}$ & $14(5.7)$ & $232(94.3)$ & 0.832 & $1.10(0.45-2.69)$ \\
\hline No & $28(18.2)$ & $126(81.8)$ & & 1 & $8(5.2)$ & $146(94.8)$ & & 1 \\
\hline \multicolumn{9}{|c|}{ Number of stressful life experiences in past 30 days } \\
\hline 0 & $7(14.3)$ & $42(85.7)$ & 0.439 & 1 & $2(4.1)$ & $47(95.9)$ & 0.929 & 1 \\
\hline $1-2$ & $18(13.1)$ & $119(86.9)$ & & $0.91(0.35-2.33)$ & $8(5.8)$ & $129(94.2)$ & & $1.46(0.30-7.11)$ \\
\hline $3-4$ & $16(11.2)$ & $127(88.8)$ & & $0.76(0.29-1.96)$ & $7(4.9)$ & $136(95.1)$ & & $1.21(0.24-6.03)$ \\
\hline $5-6$ & $11(22.0)$ & $39(78.0)$ & & $1.69(0.60-4.80)$ & $4(8.0)$ & $46(92.0)$ & & $2.04(0.36-11.71)$ \\
\hline$>6$ & $3(14.3)$ & $18(85.7)$ & & $1.00(0.23-4.31)$ & $1(4.8)$ & $20(95.2)$ & & $1.17(0.10-13.71)$ \\
\hline \multicolumn{9}{|c|}{ Symptoms of alcohol use disorder (WHO-AUDIT) ${ }^{b}$} \\
\hline Yes & $7(13.2)$ & $46(86.8)$ & 0.902 & $0.95(0.40-2.22)$ & $3(5.7)$ & $50(94.3)$ & 0.999 & $1.04(0.30-3.63)$ \\
\hline No & $48(13.8)$ & $299(86.2)$ & & 1 & $19(5.5)$ & $328(94.5)$ & & 1 \\
\hline \multicolumn{9}{|c|}{ Symptoms of substance use disorder (DAST) ${ }^{b}$} \\
\hline Yes & $2(15.4)$ & $11(84.6)$ & 0.696 & $1.15(0.25-5.31)$ & $10(76.9)$ & $3(23.1)$ & $<0.001$ & $104.17(25.37-427.71)$ \\
\hline No & $53(13.7)$ & $334(86.3)$ & & 1 & $12(3.1)$ & $375(96.9)$ & & 1 \\
\hline \multicolumn{9}{|c|}{ Anxiety symptoms (PVPS-A) b } \\
\hline Yes & $7(16.7)$ & $35(83.3)$ & 0.562 & $1.29(0.54-3.07)$ & $2(4.8)$ & $40(95.2)$ & 0.999 & $0.85(0.19-3.75)$ \\
\hline No & $48(13.4)$ & $310(86.6)$ & & 1 & $20(5.6)$ & $338(94.4)$ & & 1 \\
\hline \multicolumn{9}{|c|}{ Depressive symptoms (CES-D) ${ }^{b}$} \\
\hline Yes & $19(13.0)$ & $127(87.0)$ & 0.746 & $0.91(0.50-1.65)$ & $9(6.2)$ & $137(93.8)$ & 0.659 & $1.22(0.51-2.92)$ \\
\hline No & $36(14.2)$ & $218(85.8)$ & & 1 & $13(5.1)$ & $241(94.9)$ & & 1 \\
\hline \multicolumn{9}{|c|}{ Symptoms of HIV associated dementia (IHDS) ${ }^{\text {b }}$} \\
\hline Yes & $22(13.8)$ & $137(86.2)$ & 0.967 & $1.01(0.57-1.81)$ & $8(5.0)$ & $151(95.0)$ & 0.738 & $0.86(0.35-2.10)$ \\
\hline No & $33(13.7)$ & $208(86.3)$ & & 1 & $14(5.8)$ & $227(94.2)$ & & 1 \\
\hline
\end{tabular}

${ }^{\mathrm{a}}$ Reversed OR $=1.82 ; 95 \% \mathrm{Cl} 1.02-3.23 .{ }^{\mathrm{b}}$ Yes = Above cutoff, No = Below cutoff

examine drug use in future research, we suggest that one factor may be the difference between the samples recruited in the two studies. While the majority of Thanh et al's sample were newly-diagnosed HIV positive patients, with $54 \%$ of participants diagnosed within 1 year of HIV diagnosis [2], our study was carried out in outpatient clinics where participants had an average of 5.7 years since HIV diagnosis and most of them (99.0\%) had been taking ART for an average of 4.2 years. Across Vietnam, only 46.9\% of PLHIV receive ART [52]. To be eligible for ART, PLHIV must complete several health education and counselling workshops about HIV, ART, adherence and positive 


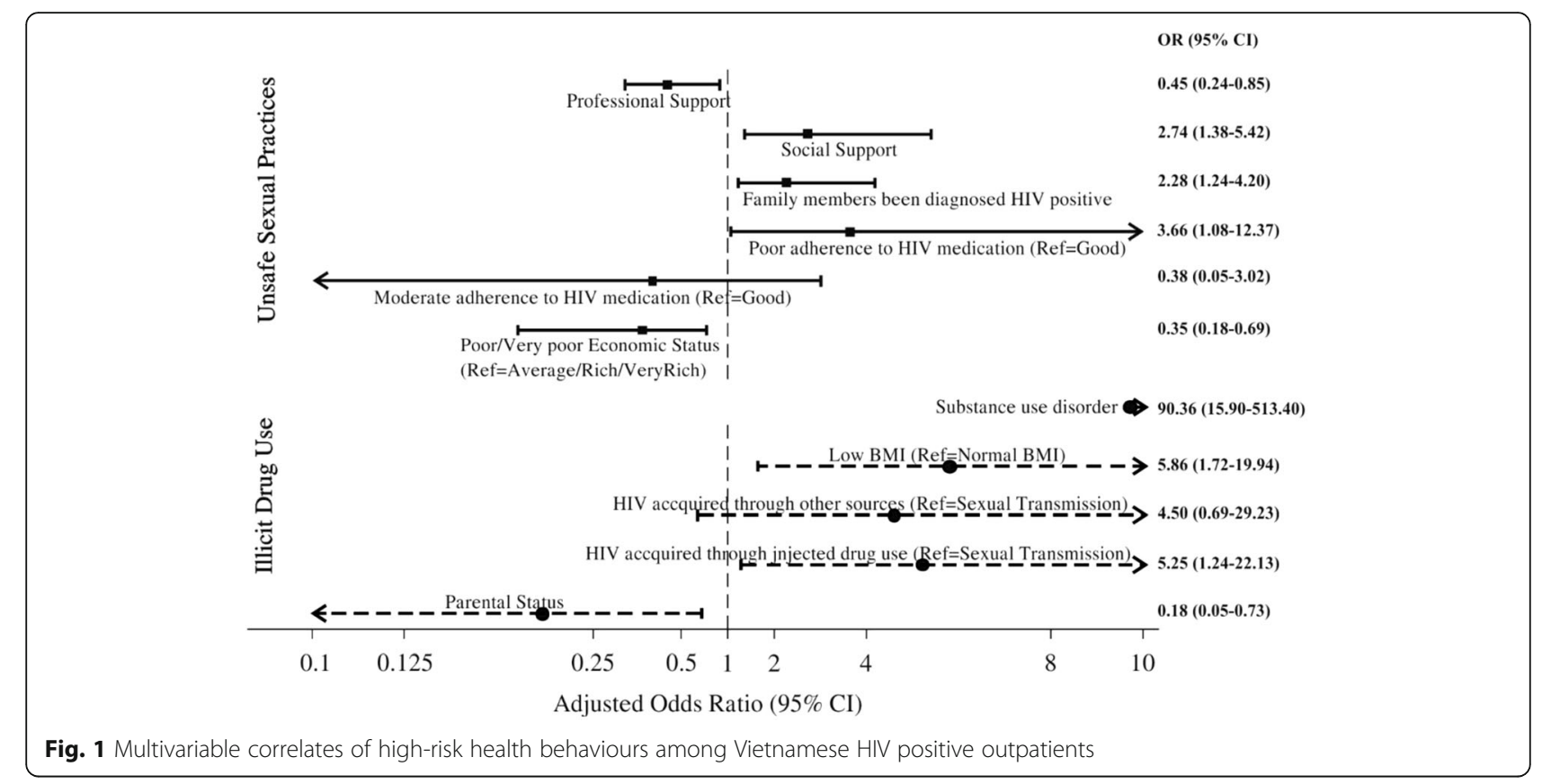

living [53]. Therefore, it is possible that the HIV positive outpatients in our study who were on ART and had attended these programs were more aware of HIV related risk behaviours, such as illicit drug use, and how these negatively impact on quality of life and thus may have reduced their drug use behaviour. In contrast, participants in Thanh et al.'s [2] study were recently diagnosed with HIV and took part in the study prior to receiving counselling and education. Consistent with this, low prevalence rates for injecting drug use, heroin, use and ecstasy, amphetamine, and cocaine use have been reported among
French HIV positive outpatients who had been on ART for an average of 6.4 years [54]. Survey data collected from 15 OPCs in HCMC in 2015 where $92 \%$ of HIV positive outpatients were on ART also found reported illicit drug use to be low [55]. Although the prevalence of illicit drug use among PLHIV was not available, a report from the Asia-Pacific region indicated prevalence of unsafe injection practices among PLHIV varied across the countries, ranging from $2 \%$ in Malaysia to $75 \%$ in Philippines [56].

The factors associated with USP in this study were consistent with previous research where HIV positive

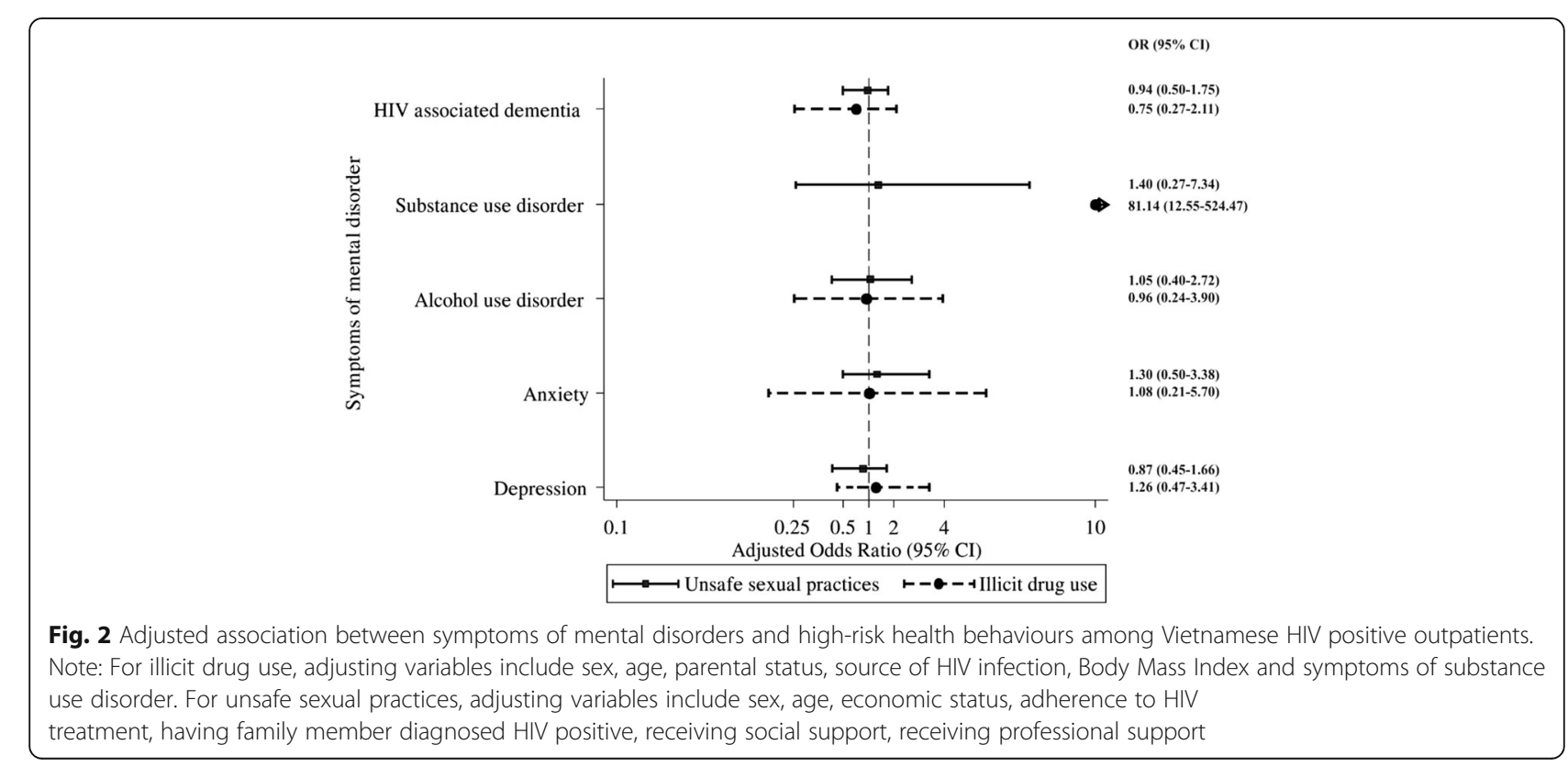


outpatients with family members diagnosed HIV positive and poor adherence to HIV medication were more likely to report USP $[3,5]$ and clinical indicators such as CD4 cell count, opportunistic diseases or any other comorbidity were not good predictors of USP [2, 5]. Given these non-significant associations we suggest that populations targeted for HRB interventions at HIV outpatient clinics should not be selected based on clinical factors alone. Targeting sub-populations for intervention should also take into account economic status since the current study demonstrated that HIV positive outpatients who perceived their economic status as poor or very poor were less likely to have USP compared to those with average or high economic status. Interestingly, we found that HIV positive outpatients who reported receiving social support had high odds of reporting USP, and those who reported professional support were less likely to report USP. However, such relationships might be affected by the complex nature of social support which warrants further investigation [57].

Similar to other studies, we found that HIV positive outpatients who had low BMI or acquired HIV through injecting drugs, as well as those with symptoms of SUD, were more likely to report illicit drug use. The link in our findings between SUD as a SOMD and illicit drug use as a HRB is not surprising, given the probable role of illicit drug use in substance abuse disorder. In contrast, HIV positive outpatients who reported that they were parents were less likely to use illicit drugs. Illicit drug use can complicate HIV treatment, reduce treatment adherence and reduce viral suppression [58]. Those who reported they had acquired HIV through injecting drug use or other substance use specifically may no longer use drugs, if their symptoms of SUD have been treated. Thus, PLHIV should be routinely screened for drug use related disorders and interventions to reduce HRB should target those with symptoms of SUD. Such routine screening and intervention during clinical care has been shown to be practical and effective in reducing HRB among PLHIV, as well as optimizing HIV treatment and improving PLHIV's quality of life [52].

Despite the view that there is an association between SOMD and HRB $[20,21]$, the current study demonstrated that HIV positive outpatients who had SOMD did not have higher odds of HRB either with or without adjusting for associated factors of HRB. Therefore, interventions for HRB should not be solely based on SOMD, except for illicit drug use among those who had symptoms of SUD. This finding supports the results of a meta-analysis of 34 studies from countries outside Vietnam where SOMD such as depression and anxiety were not significantly associated with USP [18]. One possibility as suggested by Crepaz et al. [18] was the incomplete overlap periods for the measures of SOMD and HRB. In our study, the
SOMD scales limited the symptoms to short periods, normally 1 week, while HRB were measured for a 12 month period. As such, the temporal disconnection of these measures might limit the strength of the statistical association. However, HRB measurement within a short timeframe such as 1 week and SOMD in a longer period (i.e. 12 months) also has limitations such as measurement bias. Additionally, our study did not assess for symptoms of psychosis or mania, two conditions that could have resulted in high rates of USP or illicit drug use. Finally, it may be that the relationship between SOMD and HRB in PLHIV depends on the stage of the illness and the characteristics of the sample. As noted above, our sample had completed health education and counselling workshops about HIV, ART, adherence and positive living, were receiving ART and had been living with HIV for many years.

The study had several limitations. The cross-sectional design limits explanations about the causal relationship between SOMD or other factors and HRB. Further studies using prospective cohort study designs, where SOMD and HRB are observed from ART initiation and followed up over time, are needed to clarify the causal pathway between SOMD and HRB. Despite the availability of SOMD and HRB validated screening scales, the incomplete overlap of measurement periods as discussed earlier should be taken into account in future studies. The study estimated HRB through self-report and thus participants might have experienced recall bias or may have been unwilling to accurately report these behaviours for a range of reasons including concerns about social stigma. As such, the rate of HRB found in this study might be an under-estimate. The low number of participants reporting HRB may also have limited us from finding associations between SOMD and HRB. Further research is also needed to evaluate different modes of assessing risky behaviours among Vietnamese PLHIV so that estimates can be comparable across studies and less susceptible to bias. Lastly, the study was conducted in one of the largest cities in Vietnam among HIV positive outpatients, almost all of whom were on ART. This may limit the applicability of the study findings to other populations of PLHIV in Vietnam, including PLHIV living in rural areas, PLHIV who are not on $\mathrm{ART}$ and those who are under care and treatment in hospital settings. Additionally, due to resource constraints, our sample was recruited from only two of the 30 OPCs in HCMC. While the two clinics were randomly selected and each of the 30 clinics have the same admission criteria and services for HIV positive outpatients, it is possible that there may be some differences in the sample characteristics of the HIV positive outpatients at these two clinics compared to the other OPCs. Further research in other settings in Vietnam, both in HCMC and in areas of Vietnam outside HCMC is needed. 


\section{Conclusions}

SOMD were very common among Vietnamese HIV positive outpatients however there was no association between SOMD and HRB except between symptoms of SUD and illicit drug use. Given the prevalence of SOMD identified it is likely that early screening for SOMD would lead to appropriate referral for further SOMD assessment and management. This is likely to be beneficial since early treatment of SOMD is generally more effective and provides HIV positive outpatients with better health and quality of life. Unsafe sexual practices and illicit drug use were reported by 13.8 and $5.5 \%$ of participants respectively. Further research examining the factors that predict these behaviours and the development of interventions to reduce the prevalence of HRB is crucial. Routine HIV prevention counselling during clinical care targeting HIV positive outpatients with the risk factors for USP and illicit drug use could be beneficial for patient's health, quality of life and for prevention of secondary transmission of HIV or infection with other sexually transmitted diseases.

\section{Abbreviations}

ART: Anti-Retroviral Therapy; BMI: Body mass index; CES-D: Center for Epidemiologic Studies - Depression scale; DAST: Drug Abuse Screening Test; HAD: HIV associated dementia; HCMC: Ho Chi Minh City; HRB: Health risk behaviours; IHDS: International HIV Dementia Scale; OPC: Outpatient clinic; PLHIV: People living with HIV/AIDS; PVPS-A: Phan Vietnamese Psychiatric Scale-Anxiety Scale; SOMD: Symptoms of mental disorders; USP: Unsafe sexual practices; WHO-AUDIT: World Health Organization Alcohol Use Disorder Identification Test

\begin{abstract}
Acknowledgements
The authors would like to thank the people living with HIV who participated in this study, as well as the individuals and institutions that made this research possible: Dr Tran Thinh, Dr Nguyen Hoang Tam, Dr Van Hung from Ho Chi Minh city Provincial AIDS Committee; Dr Bui Thi Thu Phuong and Dr Pham Thanh Hieu from HIV outpatient clinics; Associate Professor Do Van Dung, Mr Tran Nhat Quang, Mr Hua Thanh Liem, Ms Van Thi Thuy Duong, Ms Kim Xuan Loan from Ho Chi Minh city University of Medicine and Pharmacy; Ms Bui Thi Hy Han from Ho Chi Minh City Institute of Public Health and Dr John Nguyen, Dr Jeffrey Mendel from University of California at San Francisco.
\end{abstract}

\section{Funding}

This work was supported by The Representative Office of Abbott Laboratories S.A. in Vietnam in collaboration with Ho Chi Minh city University of Medicine and Pharmacy in HAND AWARENESS program. No Abbott products were used or recommended to be used during the study and no trademark of Abbott appeared in the study. The travel for field site work during this study was covered by the Australia Award Scholarship. Protocol development and manuscript writing was supported by CDC-PEPFAR Vietnam, the University of California, San Francisco's International Traineeships in AIDS Prevention Studies (ITAPS), U.S. NIMH, R25MH064712 and the Starr Foundation.

\section{Availability of data and materials}

Available upon request to the first author.

\section{Authors' contributions}

$\Pi$ designed the study, collected, analysed the data and drafted the manuscript. MJ, LH, RH participated in the design of the study and drafted the manuscript. All authors read and approved the final manuscript.

\section{Competing interests}

The authors declare that they have no competing interests.

\section{Consent for publication}

Not applicable.

\section{Ethics approval and consent to participate}

All procedures performed in studies involving human participants were in accordance with the ethical standards of the Human Ethics Committee at Ho Chi Minh City Provincial AIDS Committee, Vietnam (Approval number: IRB-032013, dated 17/10/2013) and the University of Sydney, Australia (Approval number: 2013/859, dated 15/11/2013). Written informed consent was obtained from all individual participants included in the study.

\section{Publisher's Note}

Springer Nature remains neutral with regard to jurisdictional claims in published maps and institutional affiliations.

\section{Author details}

${ }^{1}$ Faculty of Public Health, Ho Chi Minh City University of Medicine and Pharmacy, 159 Hung Phu Street, Ward 8, District 8, Ho Chi Minh City, Vietnam. ${ }^{2}$ Faculty of Health Sciences, University of Sydney, 75 East Street, Lidcombe, Sydney, NSW 2141, Australia. ${ }^{3}$ School of Psychological Sciences, Australian College of Applied Psychology, Level 11, 255 Elizabeth Street, Sydney, NSW 2000, Australia.

Received: 21 August 2016 Accepted: 2 March 2017

Published online: 14 March 2017

\section{References}

1. Hall HI, Holtgrave DR, Tang T, Rhodes P. HIV transmission in the United States: considerations of viral load, risk behavior, and health disparities. AIDS Behav. 2013;17(5):1632-6.

2. Thanh DC, Hien NT, Tuan NA, Thang BD, Long NT, Fylkesnes K. HIV Risk Behaviours and Determinants Among People Living with HIV/AIDS in Vietnam. AIDS Behav. 2009;13(6):1151-9.

3. Amirkhanian YA, Kelly JA, McAuliffe TL. Psychosocial needs, mental health, and HIV transmission risk behavior among people living with HIV/AIDS in St Petersburg, Russia. AIDS. 2003;17(16):2367-74.

4. Chandra PS, Desai G, Ranjan S. HIV \& psychiatric disorders. Indian J Med Res. 2005;121(4):451-67.

5. Du P, Crook T, Whitener C, Albright P, Greenawalt D, Zurlo J. HIV transmission risk behaviors among people living with HIV/AIDS: the need to integrate HIV prevention interventions and public health strategies into HIV care. J Public Health Manag Pract. 2015;21(2):E1-E10.

6. Collins PY, Holman AR, Freeman MC, Patel V. What is the relevance of mental health to HIV/AIDS care and treatment programs in developing countries? A systematic review. AIDS. 2006;20(12):1571-82.

7. Reilly T, Woo G. Predictors of High-Risk Sexual Behavior Among People Living With HIV/AIDS. AIDS Behav. 2001:5(3):205-17.

8. Kalichman SC, Eaton L, Cherry C, Kalichman MO, Pope H, White D, et al. HIV super-infection beliefs and sexual practices of people living with HIV/AIDS. Sex Health. 2010;7(4):420-4.

9. Buchacz K, Patel P, Taylor M, Kerndt PR, Byers RH, Holmberg SD, et al. Syphilis increases HIV viral load and decreases CD4 cell counts in HIVinfected patients with new syphilis infections. AIDS. 2004;18(15):2075-9.

10. Garin N, Velasco C, De Pourcq JT, Lopez B, Gutierrez Mdel M, Haro JM, et al. Recreational drug use among individuals living with HIV in Europe: review of the prevalence, comparison with the general population and HIV guidelines recommendations. Front Microbiol. 2015;6:690.

11. Pacek LR, Harrell PT, Martins SS. Cigarette smoking and drug use among a nationally representative sample of HIV-positive individuals. Am J Addict. 2014;23(6):582-90.

12. Hinkin CH, Barclay TR, Castellon SA, Levine AJ, Durvasula RS, Marion SD, et al. Drug Use and Medication Adherence among HIV-1 Infected Individuals. AIDS Behav. 2007;11(2):185-94.

13. Baum MK, Rafie C, Lai S, Sales S, Page B, Campa A. Crack-Cocaine Use Accelerates HIV Disease Progression in a Cohort of HIV-Positive Drug Users. J Acquir Immune Defic Syndr. 2009;50(1):93-9.

14. Wang XB, Tucker JD, Yang $L$, Zheng $H$, Zhang F, Cohen MS, et al. Unsafe Sex and STI Prevalence Among HIV-Infected Adults in Guangzhou, China: Opportunities to Deamplify Sexual HIV Transmission. AIDS Behav. 2013;17(3):1137-43. 
15. Kalichman SC, Eaton L, Cherry C. Sexually transmitted infections and infectiousness beliefs among people living with HIV/AIDS: implications for HIV treatment as prevention. HIV Med. 2010;11(8):502-9.

16. Loue S. Mental Health Practitioner's Guide to HIV/AIDS. Dordrecht: Springer; 2013.

17. Carrico AW. Substance use and HIV disease progression in the HAART era: implications for the primary prevention of HIV. Life Sci. 2011;88(21-22):940-7.

18. Crepaz N, Marks G. Are negative affective states associated with HIV sexual risk behaviors? A meta-analytic review. Health Psychol. 2001;20(4):291-9.

19. Kalichman SC, Weinhardt L. Negative affect and sexual risk behavior: comment on Crepaz and Marks (2001). Health Psychol. 2001;20(4):300-1.

20. Comulada WS, Rotheram-Borus MJ, Pequegnat W, Weiss RE, Desmond KA, Arnold EM, et al. Relationships over time between mental health symptoms and transmission risk among persons living with HIV. Psychol Addict Behav. 2010;24(1):109-18.

21. Crepaz N, Lyles CM, Wolitski RJ, Passin WF, Rama SM, Herbst JH, et al. Do prevention interventions reduce HIV risk behaviours among people living with HIV? A meta-analytic review of controlled trials. AIDS. 2006;20(2):143-57.

22. Nguyen NT, Keithly SC. A qualitative study on the sexual behaviour of people living with HIV in Vietnam. AIDS Care. 2012;24(7):921-8.

23. Sikkema KJ, Watt MH, Drabkin AS, Meade CS, Hansen NB, Pence BW. Mental Health Treatment to Reduce HIV Transmission Risk Behavior: A Positive Prevention Model. AIDS Behav. 2010;14(2):252-62.

24. Venkatesh KK, Srikrishnan AK, Safren SA, Triche EW, Thamburaj E, Prasad L, et al. Sexual risk behaviors among HIV-infected South Indian couples in the HAART era: implications for reproductive health and HIV care delivery. AIDS Care. 2011;23(6):722-33.

25. Bing EG, Burnam MA, Longshore D, Fleishman JA, Sherbourne CD, London AS, et al. Psychiatric disorders and drug use among human immunodeficiency virus-infected adults in the united states. Arch Gen Psychiatry. 2001;58(8):721-8.

26. Kalichman S, Rompa D. HIV treatment adherence and unprotected sex practices in people receiving antiretroviral therapy. Sex Transm Infect. 2003; 79(1):59-61.

27. Abagiu AO, Matache Dună F, Bunescu ED, Fierbințeanu IC, Popescu D, lanoş-Rancovici R, et al. How does disclosure of the HIV positive status modify drug use? BMC Infect Dis. 2013;13 Suppl 1:18.

28. Vietnam Administration of HIV/AIDS Control. A report on HIV/AIDS prevention in 2015 and priorities for 2016. Hanoi: Ministry of Health; 2016. 145/BC-BYT.

29. Gorbach PM, Ryan C, Saphonn V, Detels R. The impact of social, economic and political forces on emerging HIV epidemics. AIDS. 2002;16 Suppl 4:S35-43.

30. Green K, Tuan T, Hoang TV, Trang NN, Ha NT, Hung ND. Integrating palliative care into HIV outpatient clinical settings: preliminary findings from an intervention study in Vietnam. J Pain Symptom Manag. 2010;40(1):31-4.

31. Thai $\Pi$, Jones MK, Harris LM, Heard RC. Prevalence and correlates of symptoms of mental disorders in Vietnamese HIV-positive patients. J HIV AIDS Soc Serv. 2017;16(1):43-59.

32. Khan MR, Kaufman JS, Pence BW, Gaynes BN, Adimora AA, Weir SS, et al. Depression, sexually transmitted infection, and sexual risk behavior among young adults in the United States. Arch Pediatr Adolesc Med. 2009;163(7):644-52.

33. Esposito CA, Steel Z, Gioi TM, Huyen TT, Tarantola D. The prevalence of depression among men living with HIV infection in Vietnam. Am J Public Health. 2009;99 Suppl 2:S439-44.

34. Leserman J. Role of Depression, Stress, and Trauma in HIV Disease Progression. Psychosom Med. 2008;70(5):539-45.

35. Thompson SC, Nanni C, Levine A. The stressors and stress of being HIVpositive. AIDS Care. 1996;8(1):5-14.

36. Radloff LS. The CES-D Scale: A Self-Report Depression Scale for Research in the General Population. Appl Psychol Meas. 1977;1(3):385-401.

37. Vilagut $\mathrm{G}$, Forero CG, Barbaglia G, Alonso J. Screening for Depression in the General Population with the Center for Epidemiologic Studies Depression (CESD): A Systematic Review with Meta-Analysis. PLoS One. 2016;11(5):e0155431.

38. Phan T, Steel Z, Silove D. An Ethnographically Derived Measure of Anxiety, Depression and Somatization: The Phan Vietnamese Psychiatric Scale. Transcult Psychiatry. 2004:41(2):200-32.

39. Skinner HA. The drug abuse screening test. Addict Behav. 1982;7(4):363-71.

40. Carey KB, Carey MP, Chandra PS. Psychometric evaluation of the alcohol use disorders identification test and short drug abuse screening test with psychiatric patients in India. J Clin Psychiatry. 2003;64(7):767-74.

41. Yudko $E$, Lozhkina O, Fouts A. A comprehensive review of the psychometric properties of the Drug Abuse Screening Test. J Subst Abuse Treat. 2007; 32(2):189-98.
42. Babor TF, Biddle-Higgins JC, Saunders JB, Monteiro MG. AUDIT: The Alcohol Use Disorders Identification Test: Guidelines for Use in Primary Health Care. Geneva: World Health Organization; 2001.

43. Giang KB, Allebeck P, Spak F, Van Minh H, Dzung TV. Alcohol use and alcohol consumption-related problems in rural Vietnam: an epidemiological survey using AUDIT. Subst Use Misuse. 2008;43(3-4):481-95.

44. Tran B, Nguyen L, Do C, Nguyen Q, Maher R. Associations between alcohol use disorders and adherence to antiretroviral treatment and quality of life amongst people living with HIV/AIDS. BMC Public Health. 2014;14(1):27.

45. Sacktor NC, Wong M, Nakasujja N, Skolasky RL, Selnes OA, Musisi S, et al. The International HIV Dementia Scale: a new rapid screening test for HIV dementia. AIDS. 2005;19(13):1367-74.

46. Chishinga N, Kinyanda E, Weiss HA, Patel V, Ayles H, Seedat S. Validation of brief screening tools for depressive and alcohol use disorders among TB and HIV patients in primary care in Zambia. BMC Psychiatry. 2011;11:75.

47. Hosmer DW, Lemeshow S, Sturdivant RX. Applied logistic regression. 3rd ed. Hoboken: Wiley; 2013.

48. Skinner S, Adewale AJ, Deblock L, Gill MJ, Power C. Neurocognitive screening tools in HIV/AIDS: Comparative performance among patients exposed to antiretroviral therapy. HIV Med. 2009;10(4):246-52.

49. Saini S, Barar K. Assessment of neurocognitive functions in HIV/AIDS patients on HAART using the international HIV dementia scale. Int J Nutr Pharmacol Neurol Dis. 2014;4(4):252-5.

50. Atashili J, Gaynes B, Pence B, Tayong G, Kats D, O'donnell J, et al. Prevalence, characteristics and correlates of a positive-dementia screen in patients on antiretroviral therapy in Bamenda, Cameroon: a cross-sectional study. BMC Neurol. 2013;13(1):1-7.

51. Oshinaike OO, Akinbami AA, Ojo OO, Ojini IF, Okubadejo UN, Danesi AM. Comparison of the Minimental State Examination Scale and the International HIV Dementia Scale in Assessing Cognitive Function in Nigerian HIV Patients on Antiretroviral Therapy. AIDS Res Treat. 2012;2012:581531.

52. Fisher JD, Cornman DH, Shuper PA, Christie S, Pillay S, Macdonald S, et al. HIV prevention counseling intervention delivered during routine clinical care reduces HIV risk behavior in HIV-infected South Africans receiving antiretroviral therapy: the Izindlela Zokuphila/Options for Health randomized trial. J Acquir Immune Defic Syndr. 2014;67(5):499-507.

53. Nguyen DB, Do NT, Shiraishi RW, Le YN, Tran QH, Nguyen HH, et al. Outcomes of Antiretroviral Therapy in Vietnam: Results from a National Evaluation. PLoS One. 2013;8(2):e55750.

54. Peretti-Watel P, Spire B, Lert F, Obadia Y. Drug use patterns and adherence to treatment among HIV-positive patients: evidence from a large sample of French outpatients (ANRS-EN12-VESPA 2003). Drug Alcohol Depend. 2006; 82 Suppl 1:S71-9.

55. Ho Chi Minh City AIDS Committee. Opportunities for expanded HIV treatment as prevention in Ho Chi Minh City Vietnam: Results from the Ho Chi Minh City pre-ART HIV viral load assessment. 2014

56. UNAIDS. HIV in Asia and the Pacific-UNAIDS report; 2013. Report No: JC2558.

57. Qiao S, Li X, Stanton B. Social Support and HIV-related Risk Behaviors: A Systematic Review of the Global Literature. AIDS Behav. 2014;18(2):419-41.

58. Arnsten JH, Demas PA, Grant RW, Gourevitch MN, Farzadegan H, Howard AA, et al. Impact of Active Drug Use on Antiretroviral Therapy Adherence and Viral Suppression in HIV-infected Drug Users. J Gen Intern Med. 2002; 17(5):377-81.

\section{Submit your next manuscript to BioMed Central and we will help you at every step:}

- We accept pre-submission inquiries

- Our selector tool helps you to find the most relevant journal

- We provide round the clock customer support

- Convenient online submission

- Thorough peer review

- Inclusion in PubMed and all major indexing services

- Maximum visibility for your research

Submit your manuscript at www.biomedcentral.com/submit 